\title{
Interactions between environmental variables determine immunity in the Indian meal moth Plodia interpunctella
}

\author{
Alison Triggs and Robert J. Knell* \\ School of Biological and Chemical Sciences, Queen Mary University of London, Mile End Road, London E1 4NS, UK
}

\section{Summary}

1. Animals raised in good environmental conditions are expected to have more resources to invest in immunity than those raised in poor conditions. Variation in immune activity and parasite resistance in response to changes in environmental temperature, population density and food quality have been shown in many invertebrate species.

2. Almost all studies to date have examined the effects of individual variables in isolation. The aim of this study was to address whether environmental factors interact to produce synergistic effects on phenoloxidase (PO) activity and haemocyte count, both indicators of immune system activity. Temperature, food quality and density were varied in a fully factorial design for a total of eight treatment combinations.

3. Strong interactions between the three environmental variables led to the magnitude and in some cases the direction of the effect of most variables changing as the other environmental factors were altered. Overall, food quality had the most important and consistent influence, larvae raised on a good-quality diet having substantially higher PO activity in every case and substantially higher haemocyte counts in all treatments except unheated/low density.

4. When food quality was good, the larvae showed 'density-dependent prophylaxis': raising their investment in immunity when population density is high. When food quality was poor and the temperature low, however, those larvae raised at high densities invested less in immunity.

5. Increased temperature is often thought to lead to increased immune reactivity in ectotherms, but we found that the effect of temperature was strongly dependent on the values of other environmental variables. PO activity increased with temperature when larvae were raised on good food or when density was high, but when food was poor and density low, a higher temperature led to reduced PO activity. A higher temperature led to higher haemocyte counts when density was high and food quality was poor, but in all other cases, the effect of increased temperature was either close to zero or somewhat negative.

6. Although PO activity and haemocyte count were weakly correlated across the whole data set, there were a number of treatments where the two measures responded in different ways to environmental change. Overall, effect sizes for PO activity were substantially higher than those for haemocyte count, indicating that the different components of the immune system vary in their sensitivity to environmental change.

7. Predictions of the effect of environmental or population change on immunity and disease dynamics based on laboratory experiments that only investigate the effects of single variable are likely to be inaccurate or even entirely wrong.

Key-words: condition dependence, density-dependent prophylaxis, environmental change, parasite resistance

\section{Introduction}

The majority of, if not all, organisms are exposed to parasites during their lifetime and will therefore be selected to maintain an immune system for defence (Kraaijeveld, Ferrari \&

*Correspondence author. E-mail: a.m.triggs@qmul.ac.uk
Godfray 2002). The optimal defence theory suggests that the resources allocated to immune defence are flexible and obtained from a pool of limited resources that must fuel all fitness-related traits (Feeny 1976; Rhoades 1979; Fagerstrom et al. 1987; Simms and Rausher 1987). Thus, the resources available to allocate to immune defence must be balanced by the costs suffered to other fitness-related traits (Rigby \& 
Jokela 2000). These costs has been shown to lead to trade-offs between life-history traits and immune defence (Sheldon \& Verhulst 1996; Kraaijeveld \& Godfrey 1997; Webster \& Woolhouse 1999; Rigby \& Jokela 2000; Kraaijeveld, Limentani \& Godfray 2001; Kraaijeveld, Ferrari \& Godfray 2002), and it is therefore expected that immune responses should be condition-dependent (Sheldon \& Verhulst 1996; Lazzaro \& Little 2009). Those individuals raised in good environmental conditions should therefore have more resources to invest in their immune response than those raised in poor conditions. Evidence is accumulating to support this idea; in invertebrates, density, temperature and diet quality fluctuations have been shown to influence the ability of the immune system to deal with parasitic infection (Feder et al. 1997; Geden 1997; Fellowes, Kraaijeveld \& Godfray 1999; Liu, Gebremeskel \& Shi 2001; Sigsgaard 2000; Frid \& Myers 2002; Wilson et al. 2002).

As many invertebrates are ectothermic, environmental temperature plays an important role in maintaining bodily functions and an unfavourable environmental temperature can inhibit the immune function of an individual (Blanford \& Thomas 1999a,b; Inglis, Johnson \& Goettel 1996, 1997), with many species of invertebrates showing varying susceptibility to parasitoids and pathogens at different temperatures (Kobayashi, Inagaki \& Kawase 1981; Fellowes, Kraaijeveld \& Godfray 1999; Liu, Gebremeskel \& Shi 2001; Geden 1997; Blumberg 1991; Sigsgaard 2000; Frid \& Myers 2002; ). This temperature effect has been extensively studied by researchers investigating the use of pathogens as biological control agents, and environmental temperature has been shown to affect the virulence of many pathogens in many host systems (Adamo 1998; Blanford, Thomas \& Langewald 1998; Blanford \& Thomas 1999a,b; Blanford, Thomas \& Langewald 2000; Menti, Wright \& Perry 2000; Sigsgaard 2000; Olsen \& Hoy 2002; Frid \& Myers 2002; Blanford et al. 2003): as an example, a temperature difference as little as $2{ }^{\circ} \mathrm{C}$ has been shown to be the difference between survival and death of Zonocerus variegates infected with the fungal pathogen Entomoraga grylli (Blanford, Thomas \& Langewald 2000).

As population densities increase, environmental conditions change, and there is an increased risk of infection and of aggressive encounters with others (Anderson \& May 1981). To counter this, some animals are known to allocate more resources to their immune system at high densities: so-called density-dependent prophylaxis (DDP) (Wilson \& Reeson 1998; Wilson et al. 2001, 2002, 2003). The best examples of DDP come from phase-polyphenic insects: an increase in haemolymph phenoloxidase (PO) activity in response to higher densities has been shown in the Lepidopteran Spodoptera exempta (the African army worm) (Reeson et al. 1998; Wilson et al. 2001), and desert locusts (Schistocerca gregaria) raised under crowded conditions are more resistant to fungal infection and have a raised haemolymph antimicrobial activity (Wilson et al. 2002).

Food quality has also been shown to influence the invertebrate immune system in a number of ways. Insects that have been forced to increase their immune investment by an immunogenic challenge have reduced survival when starved (Moret
\& Schmidt-Hempel 2000; Hoang 2001) and starved insects often have reduced immune system function (Siva-Jothy \& Thompson 2002; Welburn, Maudlin \& Ellis 1989; Kubi et al. 2006; Campero et al. 2008). Food quality can also affect the number or quality of the components that make up the immune system (Szymas \& Jedruszuk 2002). For example, larvae of Rhodnius prolixus kept on blood plasma rather than their usual diet of whole blood had a significantly reduced antimicrobial activity, produced significantly lower amounts of antimicrobial peptides and were less resistant to bacterial infection (Feder et al. 1997), and Spodoptera littoralis larvae fed a lowerprotein diet have a lower resistance to viral attack than those fed a higher-protein diet, and they can 'self-medicate' by choosing to eat higher-protein foods when infected (Lee et al. 2006). In addition to simple effects from limited availability of protein, lipids and carbohydrates, the availability of micronutrients can also influence immune investment; for example, an important function of diet and feeding is the intake of antioxidants. Melanization reactions and the process of encapsulating an injury site or an intruder produce free radicals that can be responsible for invertebrate cell damage (von Schantz et al. 1999; Nappi et al. 1995; Sadd \& Siva-Jothy 2006). It has been shown that high levels of PO activity can be detrimental to longevity and survival (Schwarzenbach and Ward 2006) and that the immune system can cause damage to the tissues of the invertebrate itself (Sadd and Siva-Jothy 2006). This suggests that PO activity may not rise dramatically under good conditions owing to the limiting effect of autoimmunity; however, intake of antioxidants through diet could ameliorate this cost of mounting an immune response (Johnson \& Felton 2001; Ojala et al.2005; Babin, Clotilde \& Moret 2010).

There is therefore a reasonable amount of evidence of the impact of individual environmental variables on invertebrate immune system function, but in the field, it will be rare for one environmental factor to vary completely independently of others. Whether environmental factors interact to produce synergistic effects on the immune response is therefore an important question because if they do, then predictions from laboratory studies where animals are kept in otherwise constant environments with only one factor varying might be unreliable. To address this issue, we used the Indian meal moth Plodia interpunctella (Hübner) as a model system and compared two immune system indicators (haemocyte count and PO activity) between groups of animals raised in different environmental conditions. The density of haemocytes reflects the ability of an individual to encapsulate a wound site or intruder, as well as resist bacterial and viral attack (Eslin \& Prévost 1996), while PO is the enzyme responsible for producing the pigment melanin. Melanization is a key part of encapsulation, and PO activity has been shown to correlate with the ability of many insects to resist attack by pathogens (Rowley, Brookman \& Ratcliffe 1990; Ourth \& Renis 1993; Hagen, Grunewald \& Ham 1994; Hung \& Boucias 1996; Nigam et al. 1997; Reeson et al. 1998; Wilson et al. 2001; Cotter et al. 2004; although see Saejeng et al. 2010).

We manipulated the temperature, density and food quality in which the P. interpunctella were raised. From the 
known effects of these variables discussed above, it is possible to predict their effects on P. interpunctella in isolation: first, given that $P$. interpunctella reared on the poor diet used here have lower pupal weight, reduced fecundity and produce smaller eggs (A. Triggs and R.J. Knell, unpublished data), the poor-quality food used should produce individuals in poorer bodily condition and with a lower immune system response than those fed high-quality food. Secondly, higher densities should lead to increased investment in immune function as a prophylactic effect, and thirdly, as a small increase in temperature has been shown to increase the ability to fight infection (Blanford, Thomas \& Langewald 2000), it is predicted that those individuals raised at higher temperatures should have higher immune activity.

When more than one of these variables changes, however, the effects are harder to predict. For example, while well-fed larvae might invest more in immunity at high densities, will larvae that are already short of resources because their food supply is poor be able to do the same? If the main effect of the poor diet is energetic restriction, then higher metabolic rates at higher temperatures will exacerbate the effects of the poorer diet quality; however, if the main effect of diet quality is attributable to restriction of specific restriction, it will only affect those immune traits that require those particular components of the diet. High temperature and high density are predicted to lead to increased immune reactivity, but will the two together have additive or synergistic effects? To examine the way that these three variables interact, we carried out a fully factorial experiment, altering all three variables together to allow us to estimate interaction effects and main effects.

\section{Materials and methods}

\section{STUDY ANIMAL}

Plodia interpunctella is a small (approx. $1 \mathrm{~cm}$ length) moth that is found globally as a pest of stored food (Tzanakakis 1959). Processed grains, especially wheat, are preferred, but dried fruit, legumes, nuts, pulses and vegetables will also be consumed (Williams 1964; Sedlacek, Weston \& Barney 1996; Perez-Mendoza \& Aguilera-Pen 2004; Na \& Rayoo 2000). A stock culture of $P$. interpunctella was started using moths from three different cultures in the UK: an outbreeding culture maintained in the laboratory at the University of Liverpool for 5 years and before that at Imperial College at Silwood Park for 10 years, a second culture from the University of Sheffield and the third was a culture already maintained at Queen Mary University of London. The resulting population was reared under a $12 \mathrm{~L} / 12 \mathrm{D}$ light regime at $27^{\circ} \mathrm{C}$ and fed on $10: 1: 1$ ratio organic wheat bran (sourced from true loaf bakery): brewers yeast (Holland \& Barrett, Nuneaton, UK): glycerol (VWR) for 14 generations. For each generation, eggs were collected from at least 200 adults, and these eggs were allowed to grow to adulthood with unlimited food. There have been no signs of disease in the colony to date.

\section{EXPERIMENTAL DESIGN}

The variables manipulated were temperature $\left(30^{\circ} \mathrm{C}\right.$ vs. $\left.27^{\circ} \mathrm{C}\right)$, food quality (normal diet vs. poor diet with half as much yeast and glycerol) and density (three individuals per group vs. 10 individuals per group). These were varied in a full factorial design for a total of eight treatment combinations. Fifty groups of larvae were reared per treatment.

Over 300 adult moths from the stock culture were allowed to mate and the females to oviposit. The eggs from all the females were pooled and randomly allocated to one of the eight treatment combinations. Each group of eggs was counted into 55-mm Petri dishes and provided with ad libitum food of the appropriate quality. A square of mesh was secured across the top of each Petri dish with two elastic bands to prevent the larvae escaping, and the lid of the Petri dish was closed on top of this to prevent moisture loss from the food. The food was checked daily for signs of mould, and none was ever observed. Larvae were raised in a $27{ }^{\circ} \mathrm{C}$ controlled-temperature room under a 12:12 light/dark cycle. For the treatments with a raised temperature, the Petri dishes were placed in a single layer on a thermostatically controlled heat mat (BioGreen HMT 060-200/GB 263W, Bio Green OHG, Bischoffen-Oberweidbach, Germany) covered with a layer of aluminium foil to help distribute heat evenly across the mat. A thermostat, placed into a Petri dish filled with food medium on the heat mat, was used to keep the temperature constant; temperature was also measured and recorded throughout the experiment using a digital thermometer placed into the food medium in a dish replicating the experimental Petri dishes. Unheated treatments were placed on a similar mat that was not turned on. This design obviously introduces a degree of pseudoreplication, but we tried to reduce any confounding effects by moving the Petri dishes around on the mats several times during rearing and by keeping the heated and unheated mats next to each other on a single laboratory bench.

\section{IMMUNE FUNCTION MEASUREMENTS}

Haemolymph samples were collected from 379 P. interpunctella, 120 and 113 from the high-density treatments, high-quality and low-quality food, respectively, and 72 and 70 from the low-density treatments, high-quality and low-quality food, respectively. The haemolymph was collected at day 20 of development in the high-temperature treatment and day 23 of the lower-temperature treatment: these timings were chosen so that larvae were in the same developmental stage, namely late 5 th instar at the start of the prepupal wandering stage. All larvae were weighed, and a 2- to $3-\mu \mathrm{L}$ sample of haemolymph was extracted. This was done by piercing each individual between the final thoracic legs and the first prolegs with a fine needle and allowing a small amount of haemolymph to pool onto Parafilm.

\section{HAEMOCYTE COUNT}

One microlitres of the haemolymph was transferred to a $0 \cdot 2-\mathrm{mL}$ PCR tube using a capillary tube. Seven microlitres of phosphate-buffered saline (PBS), pH 6.8, was added to each haemolymph sample and thoroughly mixed. All $8 \mu \mathrm{L}$ of this mixture was then pipetted onto a haemocytometer. All the squares on the haemocytometer were counted and summed to give an estimate of the haemocyte density for each individual.

\section{PHENOLOXIDASE ACTIVITY ASSAY}

Phenoloxidase is present in the insect both as an inactive form (prophenoloxidase, or proPO) and as the active form, usually referred to as just PO. We chose to assay the activity of PO without converting the proPO to $\mathrm{PO}$ because this is the measure that has been shown to correlate with resistance to parasites in most cases (e.g. Nigam et al. 1997; Reeson et al. 1998; Wilson et al. 2001; Cotter et al. 2004). One microlitres of the haemolymph was transferred to a 
0.2-mL PCR tube using a capillary tube, $10 \mu \mathrm{L}$ PBS, pH 6.8, was added, and the samples were frozen to disrupt the haemocytes. When they were defrosted, samples were vortexed and transferred to a 96-well U-bottom microtitre plate (Sterilin, Newport, UK) kept on ice. Hundred microlitres of $5 \mathrm{~mm}$ dopamine was added to each sample, and plate was read on a temperature-controlled spectrophotometer, using a 492-nm filter at $28{ }^{\circ} \mathrm{C}$ (Ascent Software version 2.6; Thermo Labsystems Multiskan Ascent, Thermo Fisher Scientific, Waltham, Mass, USA). The difference in absorbance over a 20-min period was used because preliminary experiments indicated that this provided a good estimate of activity during the linear phase of the reaction.

\section{ANALYSIS}

In a design like this, the unit of replication is the group rather than the individual larva, so mean values were calculated for each Petri dish and the analysis carried out on these. General linear models were fitted to the immune function data with temperature, density and food quality plus all interactions as explanatory variables, plus weight as a covariate. PO activity was square-root-transformed to reduce heteroscedasticity and normalize errors. Non-significant terms were removed following deletion tests (Crawley 2002) to leave a minimal adequate model.

To aid in the visualization of the effects of the various environmental variables, dimensionless effect sizes (Nakagawa \& Cuthill 2007) were calculated for PO activity (square-root-transformed), haemocyte count and weight for each environmental variable for all four combinations of the other two: thus, the effect of increasing food quality was calculated for all four combinations of density and temperature, and the effect of increasing density for all combinations of food quality and temperature was also calculated. Equation 3 of Nakagawa and Cuthill was used for the effect size calculations, and the $\mathrm{R}$ script provided by Nakagawa and Cuthill and available at http://www.bio.bris.ac.uk/research/behavior/effectsize.htm was used to calculate $95 \%$ confidence intervals. All analyses were performed using R version 2.8.1 for Macintosh (R Development Core Team 2009).

\section{Results}

Initial model fits indicated that a single data point in the haemocyte data was a serious outlier, with a value far outside the normal range for this variable and that seemed to be the result of an error in recording, so this single data point was excluded from the analysis. When the model was refitted without this data point, there was a significant three-way interaction between density, food quality and temperature $\left(F_{1,83}=7 \cdot 73, \quad P=0.007\right.$; Table 1$)$ affecting haemocyte count, but weight was not significant and was removed $\left(F_{1,83}=0 \cdot 30, P=0 \cdot 59\right)$. PO activity (Table 2$)$ was determined by three significant two-way interactions: food quality and density $\left(F_{1,56}=15.59, P<0 \cdot 001\right)$, density and temperature $\left(F_{1,56}=20.13, P<0.001\right)$ and food quality and temperature $\left(F_{1,56}=12 \cdot 06, P=0 \cdot 001\right)$. Weight was once again non-significant and was removed $\left(F_{1,56}=0 \cdot 12, P=0 \cdot 28\right)$. When weight was analysed separately as a response variable (Table 3), two significant two-way interactions were apparent: temperature and density $\left(F_{1,86}=8.01, P=0.005\right)$ and temperature and food quality $\left(F_{1,86}=17.07, P<0.001\right)$.

These complex interactions between environmental variables are best visualized with the pairwise effect sizes, which are shown for all three variables in Fig. 1.

\section{HAEMOCYTE COUNT}

Food quality had the simplest effect on haemocyte count, as demonstrated by its significant main effect (Table 2).

Table 1. ANova table for the minimal model for phenoloxidase activity

\begin{tabular}{|c|c|c|c|c|c|}
\hline Source & d.f. & SS & MS & $F$ & $P$ \\
\hline Temperature & 1 & $0 \cdot 0001$ & $0 \cdot 0001$ & $0 \cdot 045$ & $0 \cdot 833$ \\
\hline Food quality & 1 & $0 \cdot 4615$ & $0 \cdot 4615$ & $205 \cdot 9$ & $<0.001$ \\
\hline Density & 1 & $0 \cdot 0010$ & $0 \cdot 0010$ & $0 \cdot 431$ & $0 \cdot 514$ \\
\hline Temperature/food quality & 1 & $0 \cdot 0230$ & $0 \cdot 0230$ & $10 \cdot 24$ & 0.002 \\
\hline Temperature/density & 1 & $0 \cdot 0371$ & $0 \cdot 0371$ & $16 \cdot 54$ & $<0.001$ \\
\hline Food/density & 1 & $0 \cdot 0362$ & $0 \cdot 0362$ & $16 \cdot 16$ & $<0.001$ \\
\hline Error & 57 & $0 \cdot 1278$ & $0 \cdot 0022$ & & \\
\hline
\end{tabular}

Deleted terms: Temperature/density/food: $F_{1,58}=1 \cdot 182, P=0 \cdot 281$; weight: $F_{1,59}=0 \cdot 108, P=0 \cdot 744$.

Table 2. ANOva table for the minimal model for log haemocyte count

\begin{tabular}{|c|c|c|c|c|c|}
\hline Source & d.f. & SS & MS & $F$ & $P$ \\
\hline Temperature & 1 & $0 \cdot 0870$ & $0 \cdot 0870$ & $0 \cdot 425$ & $0 \cdot 517$ \\
\hline Food quality & 1 & $3 \cdot 6910$ & $3 \cdot 6910$ & $18 \cdot 01$ & $<0.001$ \\
\hline Density & 1 & $0 \cdot 6326$ & $0 \cdot 6326$ & $3 \cdot 086$ & $0 \cdot 083$ \\
\hline Temperature/food quality & 1 & $0 \cdot 1516$ & $0 \cdot 1516$ & 0.739 & $0 \cdot 392$ \\
\hline Temperature/density & 1 & $0 \cdot 5063$ & $0 \cdot 5063$ & $2 \cdot 470$ & $0 \cdot 120$ \\
\hline Food quality/density & 1 & $0 \cdot 3804$ & $0 \cdot 3804$ & $1 \cdot 856$ & $0 \cdot 177$ \\
\hline Temperature/food quality/density & 1 & $1 \cdot 8921$ & $1 \cdot 8921$ & $9 \cdot 230$ & 0.003 \\
\hline Error & 83 & $17 \cdot 015$ & $0 \cdot 2050$ & & \\
\hline
\end{tabular}

Deleted term: Weight: $F_{1,84}=0 \cdot 297, P=0 \cdot 587$. 
Table 3. ANOva table for the minimal model for weight

\begin{tabular}{|c|c|c|c|c|c|}
\hline Source & d.f. & SS & MS & $F$ & $P$ \\
\hline Temperature & 1 & $251 \cdot 8$ & $251 \cdot 8$ & $27 \cdot 97$ & $<0.001$ \\
\hline Food quality & 1 & 1161 & 1161 & $129 \cdot 0$ & $<0.001$ \\
\hline Density & 1 & $26 \cdot 96$ & $26 \cdot 96$ & 2.993 & 0.087 \\
\hline Temperature/food quality & 1 & $236 \cdot 7$ & $236 \cdot 7$ & $26 \cdot 29$ & $<0.001$ \\
\hline Temperature/density & 1 & $58 \cdot 04$ & $58 \cdot 04$ & $6 \cdot 45$ & 0.013 \\
\hline Error & 86 & $774 \cdot 43$ & $9 \cdot 00$ & & \\
\hline
\end{tabular}

Deleted terms: Food quality/density: $F_{1,87}=0 \cdot 558, P=0 \cdot 457$; temperature/food quality/density: $F_{1,88}=0 \cdot 968, P=0 \cdot 328$.

Fig. 1. Dimensionless effect sizes (essentially, the number of standard deviations that the mean changes by given a particular treatment) and $95 \%$ confidence intervals calculated for each pairwise contrast within the experimental design. Open circles indicate effects on square-root-transformed phenoloxidase (PO) activity, closed circles effects on haemocyte count and closed triangles effects on weight. The top panel shows the effect of increasing density from three larvae per group to 10; the centre panel the effect of increasing food quality by doubling the amount of yeast and glycerol in the diet and the bottom panel the effect of increasing the temperature from 27 to $30^{\circ} \mathrm{C}$.

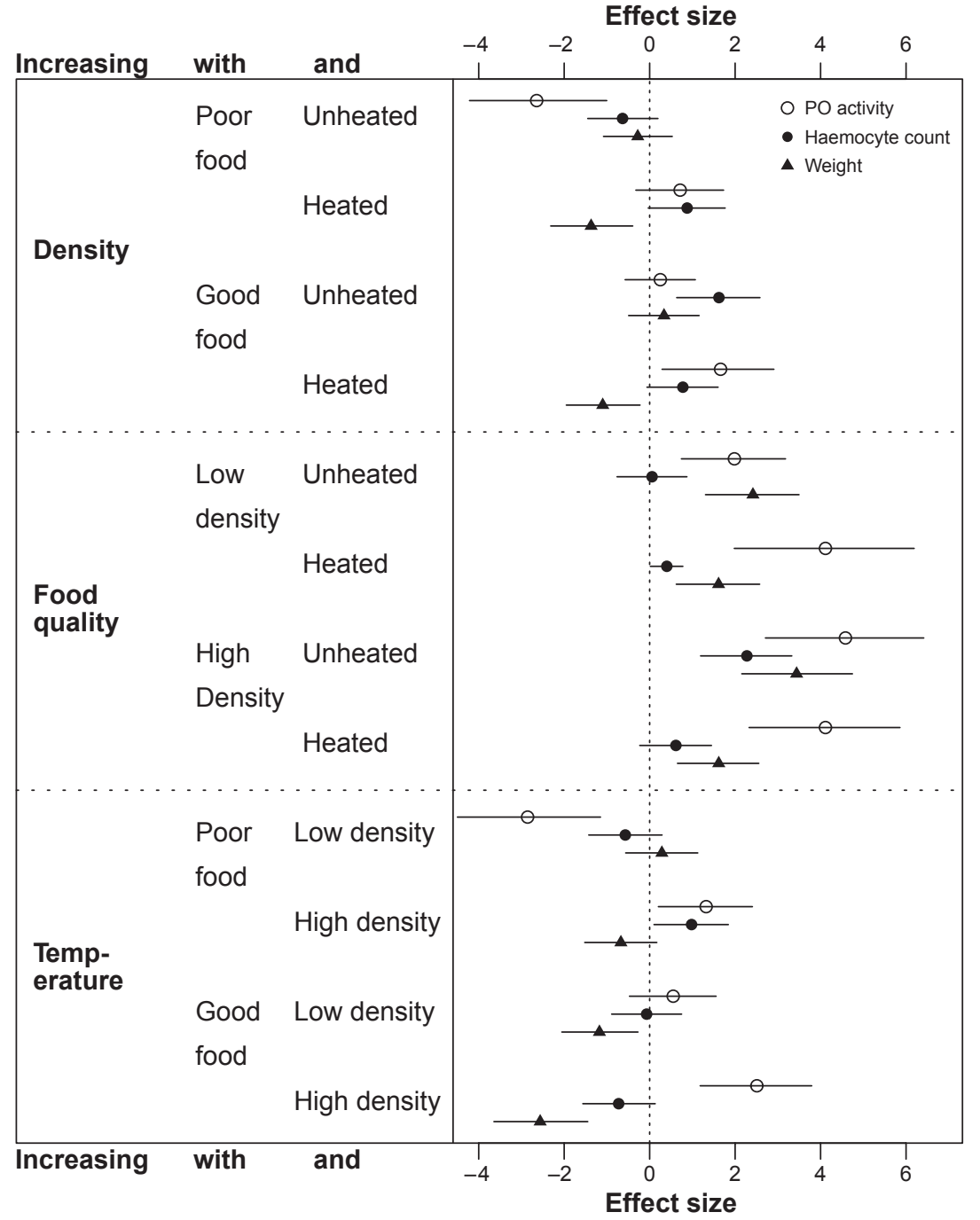

The three-way interaction between density, temperature and food quality is evident here as well however, and when food quality was poor and the temperature was low, the effect of increasing density was reversed.

A higher temperature was only associated with higher haemocyte counts when food quality was poor and density was high (Fig. 1); in most other treatment combinations, haemocyte count was lower in those larvae raised at a higher temperature or was unaffected by temperature (as in the lowdensity/good food treatment).
Regarding density, in most cases, the larvae from the highdensity treatments had higher haemocyte counts (Fig. 1).
Larvae raised on the good-quality diet had higher haemocyte counts in every case except in the unheated/lowquality interacted with both density and temperatur as can be seen in Fig. 1, the strength of the effect of increasing food quality varied substantially, with the strongest effect being seen when the animals were unheated and the temperature was high.

(c) 2011 The Authors. Journal of Animal Ecology ( 2011 British Ecological Society, Journal of Animal Ecology 


\section{PHENOLOXIDASE ACTIVITY}

Larvae raised on the good-quality diet had much higher PO activity in every case, with estimated effect sizes in excess of four in three of four cases (Fig. 1). In addition to this strong main effect, food quality also interacted with both density and temperature, and these two variables also interacted with each other to produce a complicated pattern of different effects.

Increasing density when food quality was good led to higher PO activity only when the larvae were heated. When food quality was poor, the effect of increasing density changed, with a small positive effect observed in the heated treatment, but in the unheated treatment, a strong negative effect, with the low-density treatments expressing higher PO activity (Fig. 1).

When density was high, increasing temperature led to higher scores for PO activity. When density was low, however, increasing temperature led to either a small positive effect when food quality was good or a strong negative effect when the food was poor (Fig. 1).

\section{WEIGHT}

As with PO activity, increasing food quality led to heavier larvae in every case (Fig. 1), with the significant temperatureby-food interaction being shown by the very strong effects in the unheated treatments (effect size $2 \cdot 4$ for low density and 3.4 for high density). The density-by-temperature interaction can also be clearly seen in the top panel of Fig. 1, with increasing density having a small or no effect on weight in the unheated treatments but strong negative effects in the heated treatments. Increasing temperature led to decreased weight in most cases, with a particularly strong effect in the highdensity/good food treatment, but there was essentially no effect of increased temperature on weight in the poor food/low-density treatment.

\section{COMPARING THE RESPONSES OF PO ACTIVITY AND HAEMOCYTE COUNT}

The two components of the immune system that we measured did not always respond in the same way to environmental changes. Although PO activity correlated with haemocyte count in the data set as a whole $(r=0 \cdot 375,60$ d.f., $P=0 \cdot 0026)$, there were some combinations of environmental variables where only one component of the immune system was affected: for example, increasing food quality in the low-density/unheated treatment caused a substantial increase in PO activity but did not affect haemocyte count, and increasing density in the good food: unheated treatment caused a considerable increase in haemocyte count but had little effect on PO activity. Furthermore, the magnitude of the effects of the various environmental factors on the two variables and on weight differed, with PO activity generally showing substantially larger effect sizes than haemocyte count and weight, having effect sizes intermediate between

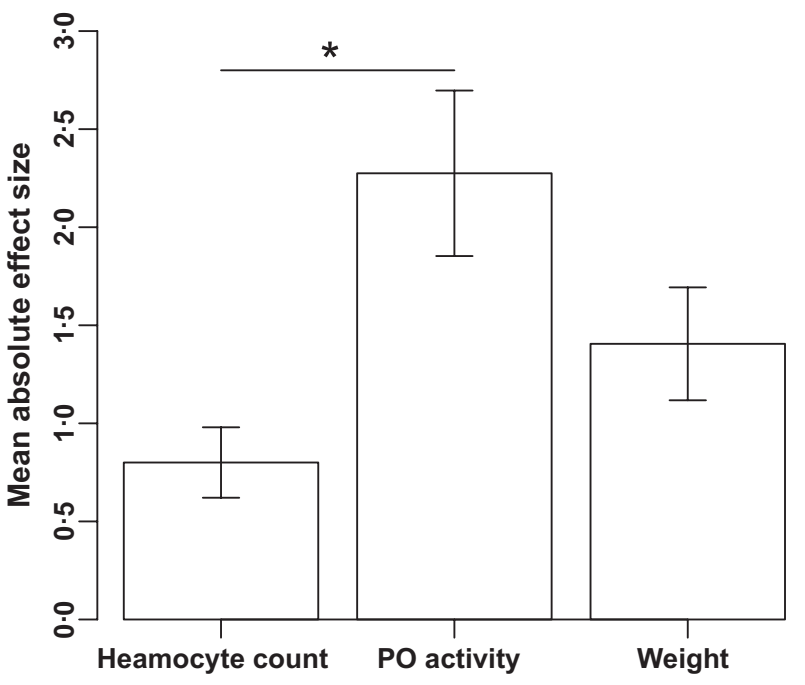

Fig. 2. Mean absolute (i.e. unsigned) effect sizes for haemocyte count, square-root phenoloxidase (PO) activity and weight. Error bars indicate one standard error. Haemocyte count and PO activity are significantly different from each other (Tukey HSD test, $P=0 \cdot 017)$, but neither is significantly different from weight.

the two (Fig. 2, Anova, $F_{2,33}=4 \cdot 30, P=0 \cdot 0219$, absolute effect size log-transformed to correct heteroscedasticity).

\section{Discussion}

Like many other studies, we find that the environment experienced by a developing animal has a profound effect on its immune system. The data presented here extend our understanding by demonstrating that the effects of the three environmental factors that we investigated are dependent not only on the level of the individual factor but also on other aspects of the environment. This leads to a rich variety of final effects, with the effects of one variable sometimes even being reversed when another variable changes.

The main effect of food quality, with larvae raised on the better food mostly having stronger immune reactivity, is what would be predicted from the resource allocation theories discussed in the introduction, whereby the limited pool of resources available to a developing animal means that investment in any one fitness component, such as immunity, must be traded off against investment in others (Sheldon \& Verhulst 1996) owing to resource constraints on the individual. Environmental conditions such as temperature and population density act to further constrain the developing larvae and to limit their ability to invest in immunity. The nature of the interactions between food quality and density also make sense in the light of resource allocation theory.

The increased immune investment found in larvae reared at high densities under most combinations of food quality and temperature is consistent with the DDP hypothesis, which predicts that there should be an increase in investment in immunity at high population densities, a phenomenon that has been described from a number of other insect systems (Wilson \& Reeson 1998; Barnes \& Siva-Jothy 2000; Wilson 
2000; Wilson et al. 2002, 2003). In the unheated treatment, however, poor food quality led to lower immune reactivity at higher densities, apparently reversing the effect of density: it appears that when resources are plentiful, the larvae invest more into immunity at higher densities, but that the combined impact of both high density and poor food leads to severe resource limitation that prevents them from investing in immunity. As food was provided ad libitum, there should not have been any direct competition for food; however, those raised at high density might have spent more time and energy on aggressive encounters with others rather than on feeding and growing.

The contrast between the effects of density on immune reactivity and weight is also noteworthy. In unheated treatments, increasing density had little effect on weight, whereas in the heated treatments, increasing density led to a negative effect on weight but positive effects on both immune parameters. It is possible that this is the consequence of these animals trading off investment in body size against investment in immunity at higher temperatures, but as the effect sizes are similar for both food treatments, this seems unlikely: a more parsimonious explanation is that at high temperatures, weight and immunity respond differently to density because they are controlled by different developmental mechanisms rather than because they are directly coupled by resource availability.

A number of previous studies have found that insects with a higher body temperature are more likely to survive viral, fungal, bacterial, microsporidial and even macroparasitic infections (Blanford, Thomas \& Langewald 2000; Carruthers et al. 1992; Kobayashi, Inagaki \& Kawase 1981; Mohamed, Coppel \& Podgwaite 1985; Adamo 1998; Olsen \& Hoy 2002; Frid \& Myers 2002; Thomas \& Blanford 2003) and that they even behaviourally induce 'fever' when they are infected (Karban 1988; McClain, Magnuson \& Warner 1988; Watson, Mullens \& Petersen 1993; Adamo 1998; Blanford, Thomas \& Langewald 1998). Direct effects of temperature on haemocyte counts have also been reported: a gradual increase in temperature from 10 to $20{ }^{\circ} \mathrm{C}$ caused a significant increase in haemocyte number in the crab Carcinus maenus (Truscott \& White 1990), and total haemocyte number was found to be significantly higher in the two crayfish species Pacifastacus leniusculus and Astacus astacus when kept at $18{ }^{\circ} \mathrm{C}$ rather than at $4{ }^{\circ} \mathrm{C}$ (Jiravanichpaisal, Söderhäll \& Söderhäll 2004). These results might lead us to expect a general increase in immune investment in the high-temperature treatments, but we found that higher temperatures could lead to both increases and decreases in immune reactivity and that in the case of the good food/high-density treatment, the different components of the immune system responded very differently to temperature.

It is possible that some of the effects of temperature were attributable to larvae at the higher temperatures becoming more dehydrated, but we consider this unlikely: the temperature differences were not large, all experimental dishes had plastic lids that would minimize evaporation, and Plodia are a pest of dried, stored grain products and appear to be able to survive with very little dietary water intake (Williams 1964;
Sedlacek, Weston \& Barney 1996; Perez-Mendoza \& Aguilera-Pen 2004; Na \& Rayoo 2000).

Even when the increased temperature did lead to an improved immune response, there could still have been a cost to the animal. Individuals with a larger body size tend to have increased fitness and fecundity than smaller individuals from the same population (Bonner 2006), and those raised at a hotter temperature often reach a smaller body size than those raised at a cooler temperature (Kingsolver \& Huey 2008). This was the case in this study where, in most cases, the $P$. interpunctella larvae raised at the higher temperature were lighter, especially in the good food treatments, perhaps owing to faster development rates (Johnson, Wofford \& Whitehand 1992). Smaller sizes with higher temperatures are not always the case: in the poor food/low-density treatment, increasing temperature had no effect on larval weight, and there are reports from the literature of increasing temperature leading to larger body sizes in other lepidopteran species such as Parasemia plantaginis, which has a slower development time and lower growth rate at colder temperatures (Lindstedt, Lindstrom \& Mappes 2009). This suggests that the response of growth to temperature is rather species specific. Because fecundity increases with body size across many insect taxa (Honěk 1993), it is possible that, in our study, individuals raised at higher temperatures pay a cost in the form of reduced fecundity, although we should note that Johnson, Wofford \& Whitehand (1992) showed that P. interpunctella raised on a bran diet at $31.7^{\circ} \mathrm{C}$ produced more progeny than those raised at 25 and $28 \cdot 3{ }^{\circ} \mathrm{C}$.

The analysis using effect sizes allows a direct comparison of the way that two components of the immune system, plus body weight, respond to environmental changes. Immunity is usually regarded as being 'condition-dependent' and sensitive to changes in resource availability and other aspects of an animal's environment (e.g. Møller et al. 1998; Siva-Jothy $\&$ Thompson 2002). These results show that the strength of condition dependence varies widely between components of the immune system; the mean effect size for haemocyte count in this experiment was $0 \cdot 80$, whereas that for PO activity was $2 \cdot 27$ (Fig. 2). All of these are 'large' effects by the criteria proposed by Cohen (1998, see also comments on these criteria in Nakagawa \& Cuthill 2007), but the difference between haemocyte count and PO activity emphasizes the dangers in regarding immune reactivity as a single, measurable variable.

This study demonstrates the importance of considering interactions between different environmental variables when trying to understand the evolutionary ecology of immune responses. When an individual variable is studied in isolation, important interactions and their effects may be overlooked, and these interactions could cause laboratory studies, where animals are kept in otherwise constant environments, to produce unreliable predictions of immune function in natural systems. One obvious example where the lessons from the present study indicate caution is the predictions for how anthropogenic climate change on Earth might affect host/pathogen dynamics and infection rates. Some studies 
predict an increase in pathogen virulence owing to accelerated growth and increased transmission rates (Harvell et al. 2002; Mydlarz, Jones \& Harvell 2006), while others have predicted reductions in virulence, owing to the parasite no longer being at optimum temperature or to improved host immune system function associated with a higher temperature (Blanford et al. 2003). Our study shows that a small temperature increase can produce an effect on invertebrate immune system function, but that the nature of the effect of temperature will depend on other environmental effects, meaning that future changes in host/pathogen dynamics in natural environments are likely to be less predictable than we might hope.

\section{Acknowledgements}

We thank three anonymous referees for their helpful suggestions regarding how to improve previous versions of the manuscript.

\section{References}

Adamo, S.A. (1998) The specificity of behavioural fever in the cricket Acheta domesticus. Journal of Parasitiology, 84, 529-533.

Anderson, R.M. \& May, R.M. (1981) The population dynamics of microparasites and their invertebrate hosts. Philosophical Transactions of the Royal Society of London, Series B-Biological Sciences, 291, 451-524.

Babin, A., Clotilde, B. \& Moret, Y. (2010) Dietary supplementation with carotenoids improves immunity without increasing its cost in a crustacean. American Naturalist, 176, 234-241.

Barnes, A.I. \& Siva-Jothy, M.T. (2000) Density-dependent prophylaxis in the mealworm beetle Tenebrio molitor L. (Coleoptera: Tenebionidae): cuticular melanisation is an indicator of investment in immunity. Proceedings of the Royal Society of London, Series B-Biological Sciences, 267, 177-182.

Blanford, S. \& Thomas, M.B. (1999a) Host thermal biology: the key to understanding insect-pathogen interactions and microbial pest control? Agricultural and Forest Entomology, 1, 195-202.

Blanford, S. \& Thomas, M.B. (1999b) Role of thermal biology in disease dynamics. Aspects of Applied Biology, 53, 73-82.

Blanford, S., Thomas, M.B. \& Langewald, J. (1998) Behavioural fever in the Senegalese grasshopper, Oedaleus senegalensis, and its implications for biological control using pathogens. Ecological Entomology, 23, 9-14.

Blanford, S., Thomas, M.B. \& Langewald, J. (2000) Thermal ecology of Zonocerus variegates. Agricultural and Forest Entomology, 2, 3-10.

Blanford, S., Thomas, M.B., Pugh, C. \& Pell, J.K. (2003) Temperature checks the Red Queen? Resistance and virulence in a variable environment. Ecology Letters, 6, 2-5.

Blumberg, D. (1991) Seasonal variations in the encapsulation of eggs of the encyrtid parasitoid, Metaphycus stanleyi, by the pyriform scale, Protopulvinaria pyriformis. Entomologia Experimentalis et Applicata, 58, 231-237.

Bonner, J.T. (2006) Why Size Matters. Princeton University Press, Princeton, NJ.

Campero, M., De Block, M., Ollevier, F. \& Stoks, R. (2008) Correcting the short-term effect of food deprivation in a damselfly: mechanisms and costs. Journal of Animal Ecology, 77, 66-73.

Carruthers, R.I., Larkin, T.S., Firstence, H. \& Feng, Z. (1992) Influence of thermal ecology on the mycosis of a rangeland grasshopper. Ecology, 73, 190-204.

Cohen, J. (1998) Statistical Power Analysis for the Behavioural Sciences, 2nd edn. Erlbaum, Hillsdale, NJ.

Cotter, S.C., Hails, R.S., Cory, J.S. \& Wilson, K. (2004) Density-dependant prophylaxis and condition-dependant immune function in Lepidopteran larvae: a multivariate approach. Journal of Animal Ecology, 73, 283-293.

Crawley, M.J. (2002) Statistical Computing: An Introduction to Data Analysis Using S-Plus. Wiley-Blackwell, Chichester, UK

Eslin, P. \& Prévost, G. (1996) Variation in Drosophila concentration of haemocytes associated with different ability to encapsulate Asobara tabida larval parasitoid. Journal of Insect Physiology, 42, 549-555.

Fagerstrom, J.A. (1987) The Evolution of Reef Communities. John Wiley and Sons Inc., New York, NY.
Feder, D., Mello, C.B., Garcia, E.S. \& Azambuja, P. (1997) Immune reactions in Rhodnius prolixus: influence of nutrition and ecdysone. Journal Insect Physiology, 43, 513-519.

Feeny, P. (1976) Plant Apparency and Chemical Defense. Recent Advances in Phytochemistry, Vol. 10, pp. 1-40. Plenum Press, New York, NY.

Fellowes, M.D.E., Kraaijeveld, A.R. \& Godfray, C.J. (1999) Cross resistance following artificial selection for increased host defence against parasitoids in Drosophila melanogaster. Evolution, 53, 966-972.

Frid, L. \& Myers, J.H. (2002) Thermal ecology of western tent caterpillars, Malacosoma californnicum pluviale, and infection by nucleopolyhedrovirus. Ecological Entomology, 27, 665-673.

Geden, C.J. (1997) Development models for the filth fly parasitoids Spalangia gemina, S. cameroni and Muscidifurax raptor (Hymenoptera: Pteromalidae) under constant and variable temperatures. Biological Control, 9, 185-192.

Hagen, H.E., Grunewald, J. \& Ham, P.J. (1994) Induction of the prophenoloxidase-activating system of Simulium (Diptera: Simuliidae) following Onchocerca (Nematoda: Filarioidea) infection. Parasitology, 109, 649-655.

Harvell, C.D., Mitchell, C.E., Ward, J.R., Altizer, S., Dobson, A.P., Ostfeld, R.S. \& Samuel, M.D. (2002) Climate warming and disease risks for terrestrial and marine biota. Science, 296, 2158-2162.

Hoang, A. (2001) Immune response to parasitism reduces resistance of Drosophila melanogaster to desiccation and starvation. Evolution, 55, 23532358.

Honěk, A. (1993) Intraspecific variation in body size and fecundity in insects: a general relationship. Oikos, 66, 483-492.

Hung, S.Y. \& Boucias, D.G. (1996) Pheoloxidase activity in the haemolymph of naïve and Beauvaria bassiana infected Spodoptera exigua larvae. Journal of Invertebrate Pathology, 67, 35-40.

Inglis, G.D., Johnson, D.L. \& Goettel, M.S. (1996) Effects of temperature and thermoregulation on mycosis by Beauveria bassiana in grasshoppers. Biological Control, 7, 131-139.

Inglis, G.D., Johnson, D.L. \& Goettel, M.S. (1997) Effects of temperature and sunlight on mycosis (Beauveria bassiana) (Hyphomycetes: Sympodulosporae) of grasshoppers under field conditions. Environmental Entomology, 26, 400- 409 .

Jiravanichpaisal, P., Söderhäll, K. \& Söderhäll, I. (2004) Effect of water temperature on the immune response and infectivity pattern of white spot syndrome virus (WSSV) in freshwater crayfish. Fish \& Shellfish Immunology, 17, 265-275.

Johnson, K.S. \& Felton, G.W. (2001) Plant phenolics as dietary antioxidants for insects: a test with genetically modified tobacco. Journal of Chemical Ecology, 27, 2579-2597.

Johnson, J.A., Wofford, P.L. \& Whitehand, L.C. (1992) Effect of diet and temperature on development rates, survival, and reproduction of the Indian meal moth (Lepidoptera, Pyralidae). Journal of Economic Entomology, 85, 561-566.

Karban, R. (1988) Caterpillar basking behaviour and nonlethal parasitism by tachinid flies. Journal of Insect Behaviour, 11, 714-723.

Kingsolver, J.G. \& Huey, R.B. (2008) Size, temperature, and fitness: three rules. Evolutionary Ecology Research, 10, 251-268.

Kobayashi, M., Inagaki, S. \& Kawase, S. (1981) Effect of high temperature on the development of nuclear polyhedrosis virus in the silkworm, Bombyx mori. Journal of Invertebrate Pathology, 38, 386-394.

Kraaijeveld, A.R., Ferrari, J. \& Godfray, H.C.J. (2002) Costs of resistance in insect-parasite and insect-parasitoid interactions. Parasitology, 125, S71S82.

Kraaijeveld, A.R. \& Godfrey, H.C.J. (1997) Trade-off between parasitoid resistance and larval competitive ability in Drosophila melanogaster. Nature, $\mathbf{3 8 9}$ 278-280.

Kraaijeveld, A.R., Limentani, E.C. \& Godfray, H.C.J. (2001) Basis of the trade-off between parasitoid resistance and larval competitive ability in Drosophila melanogaster. Proceedings of the Royal Society of London, Series B-Biology Sciences, 268, 259-261.

Kubi, C., van den Abbeele, J., de Deken, R., Marcotty, T., Dorny, P. \& van den Bossche, P. (2006) The effect of starvation on the susceptibility of teneral and non-teneral tsetse flies to trypanosome infection. Medical and Veterinary Entomology, 20, 388-392.

Lazzaro, B.P. \& Little, T.J. (2009) Immunity in a variable world. Philosophical Transactions of the Royal Society B: Biological Sciences, 364, 15-26.

Lee, K.P., Cory, J.S., Wilson, K., Raubenheimer, D. \& Simpson, S.J. (2006) Flexible diet choice offsets protein costs of pathogen resistance in a caterpillar. Proceedings of the Royal Society B-Biological Sciences, 273 823-829.

Lindstedt, C., Lindström, L. \& Mappes, J. (2008) Thermoregulations constrains effective warning signal expression. Evolution, 63, 469-478. 
Liu, S., Gebremeskel, F.B. \& Shi, Z. (2001) Reproductive compatibility and variation in survival and sex ratio between two geographic populations of Diadromus collaris (Hymenoptera:Ichneumonidae), a pupal parasitoid of the diamondback moth, Plutella xylostella (Lepidoptera: Plutellidae), and its interaction with Oomyzus sokolowskii (Hymenoptera: Eulophidae). Bulletin of Entomological Research, 91, 461-469.

McClain, E., Magnuson, P. \& Warner, S.J. (1988) Behavioural fever in a Namib desert tenebrionid beetle, Onymacris plana. Journal of Insect Physiology, 34, 279-284.

Menti, H., Wright, D.J. \& Perry, R.N. (2000) Infectivity of populations of the entomopathogenic nematodes Steinernema feltiae and Heterorhabditis megidis in relation to temperature, age and lipid content. Nematology, $\mathbf{2}$, 515-521.

Mohamed, M.A., Coppel, H.C. \& Podgwaite, J.D. (1985) Temperature and crowding effects on virus manifestation in Neodiprion sertifer (Hymenoptera: Diprionidae) larvae. Great Lakes Entomologist, 18, 115-118.

Møller, A.P., Christe, P., Erritzoe, J. \& Meller, A.P. (1998) Condition, disease and immune defence. Oikos, 83, 301-306.

Moret, Y. \& Schmidt-Hempel, P. (2000) Survival for immunity: the price of immune system activation for bumblebee workers. Science, 290, 116-1168.

Mydlarz, L.D., Jones, L.E. \& Harvell, C.D. (2006) Innate immunity, environmental drivers, and disease ecology of marine and freshwater invertebrates. Annual Review of Ecology, Evolution and Systematics, 37, 251-288.

Na, J.H. \& Ryoo, M.I. (2000) The influence of temperature on development of Plodia interpunctella (Lepidoptera: Pyralidae) on dried vegetable commodities. Journal of Stored Products Research, 36, 125-129.

Nakagawa, S. \& Cuthill, I. (2007) Effect size, confidence interval and statistical significance: a practical guide for biologists. Biological Reviews, 82, 591-605.

Nappi, A.J., Vass, E., Frey, F. \& Carton, Y. (1995) Superoxide anion generation in Drosophila during melanotic encapsulation of parasites. European Journal of Cell Biology, 68, 450-456.

Nigam, Y., Maudlin, I., Welburn, S. \& Ratcliffe, N.A. (1997) Detection of phenoloxidase activity in the hemolymph of tsetse flies, refractory and susceptible to infection with Trypanosoma brucei rhodensie. Journal of Invertebrate Pathology, 69, 279-281.

Ojala, K., Julkunen-Tiitto, R., Lindstroem, L. \& Mappes, J. (2005) Diet affects the immune defence and life-history traits of an Arctiid moth Parasemia plantaginis. Evolutionary Ecology Research, 7, 1153-1170.

Olsen, L.E. \& Hoy, M.A. (2002) Heat curing Metaseilus occidentalis (Nesbit) (Acari, Phytoseiidae) of a fitness-reducing microsporidium. Journal of Invertebrate Pathology, 79, 173-178.

Ourth, D.D. \& Renis, H.E. (1993) Antiviral melanisation reaction of Heliothis virescens haemolymph against DNA and RNA viruses in vitro. Comparative Biochemistry and Physiology, 105B, 719-723.

Perez-Mendoza, J. \& Aguilera-Pen, M. (2004) Development, reproduction, and control of the Indian meal moth, Plodia interpunctella (Hübner) (Lepidoptera:Pyralidae), in stored seed garlic in Mexico. Journal of Stored Products Research, 40, 409-421.

R Development Core Team (2009) R: a language and environment for statistical computing. R Foundation for Statistical Computing, Vienna, Austria. http://www.R-project.org.

Reeson, A.F., Wilson, K., Gunn, A., Hails, R.S. \& Goulson, D. (1998) Baculovirus resistance in the noctuid Spodoptera exempta is phenotypically plastic and responds to population density. Proceedings of the Royal Society of London, Series B-Biology Sciences, 265, 1787-1791.

Rigby, M.C. \& Jokela, J. (2000) Predator avoidance and immune defence: costs and trade-offs in snails. Proceedings of the Royal Society B-Biological Sciences, 267, 171-176.

Rhoades, D. F. (1979) Evolution of plant chemical defense against herbivores. Herbivores: Their Interaction with Secondary Plant Metabolites (eds G.A. Rosenthal \& D.H. Janzen), pp. 3-54. Academic Press, New York, NY.

Rowley, A.F., Brookman, J.L. \& Ratcliffe, N.A. (1990) Possible involvement of the prophenoloxidase system of the locust, Locusta migratoria, in antimicrobial activity. Journal of Invertebrate Pathology, 56, 31-38.
Sadd, B.M. \& Siva-Jothy, M.T. (2006) Self-harm caused by an insect's innate immunity. Proceedings of the Royal Society of London B-Biological, 273 , 2571-2574.

Saejeng, A., Tidbury, H., Siva-Jothy, M.T. \& Boots, M. (2010) Examining the relationship between hemolymph phenoloxidase and resistance to a DNA virus, Plodia interpunctella granulosis virus (PiGV). Journal of Insect Physiology, 56, 1232-1236.

von Schantz, T., Bensch, S., Grahn, M., Hasselquist, D. \& Witzell, H. (1999) Good genes, oxidative stress, and condition dependent signals. Proceedings of the Royal Society of London B-Biological, 266, 1-12.

Schwarzenbach, G.A. \& Ward, P.I. (2006) Responses to selection on phenoloxidase activity in yellow dung flies. Evolution, 60, 1612-1621.

Sedlacek, J.D., Weston, P.A. \& Barney, J. (1996) Lepidoptera and Psocoptera Integrated Management of Insects in Stored Products (eds B. Subramanyam \& D.W. Hagstrum), pp. 41-70. Marcel Dekker Inc., New York, NY.

Sheldon, B.C. \& Verhulst, S. (1996) Ecological immunology: costly parasite defenses and trade-offs in evolutionary ecology. Trends in Ecology and Evolution, 11, 317-321.

Sigsgaard, L. (2000) The temperature-dependent duration of development and parasitism of three cereal aphid parasitoids, Aphidius ervi, A. rhopalosiphi and Praon volucre. Entomologia Experimentalis et Applicata, 95, 173-184.

Simms, E.L. \& Rauscher, M.D. (1987) Costs and benefits of plant resistance to herbivory. American Naturalist, 130, 570-581.

Siva-Jothy, M.T. \& Thompson, J.J.W. (2002) Short-term nutrient deprivation affects immune function. Physiological Entomology, 27, 206-212.

Szymas, B. \& Jedruszuk, A. (2002) The influence of different diets on haemocytes of adult worker honey bees, Apis mellifera. Apidologie, 34, 97-102.

Thomas, M.B. \& Blanford, S. (2003) Thermal biology in insect parasite interactions. Trends in Ecology and Evolution, 18, 344-350.

Truscott, R. \& White, K.N. (1990) The influence of metal and temperature stress on the immune system of crabs. Functional Ecology, 4, 455-461.

Tzanakakis, M.E. (1959) An ecological study of the Indian-meal moth Plodia interpunctella (Hübner) with emphasis on diapause. Hilgardia, 29, 205-246.

Watson, D.W., Mullens, B.A. \& Petersen, J.J. (1993) Behavioural fever response of Musca domestica (Diptera: Muscidae) to infection by Enteromorpha muscae (Zygomycetes: Entomorphthorales). Journal of Invertebrate Pathology, 61, 10-16.

Webster, J.P. \& Woolhouse, M.E.J. (1999) Cost of resistance: relationship between reduced fertility and increased resistance in a snail-schistosome host-parasite system. Proceedings of the Royal Society B-Biological Sciences, 266, 391-396.

Welburn, S.C., Maudlin, I. \& Ellis, D.S. (1989) Rate of trypanosome killing by lectins in midguts of different species and strains of Glossina. Medical and Veterinary Entomology, 3, 77-82.

Williams, G.C. (1964) The life-history of the Indian meal-moth, Plodia interpunctella (Hübner) (Lep. Phycitidae) in a warehouse in Britain and on different foods. Annals of Applied Biology, 53, 459-475.

Wilson, K. (2000) How the locust got its stripes: the evolution of density-dependent aposematism. Trends in Ecology and Evolution, 15, 88-90.

Wilson, K. \& Reeson, A.F. (1998) Density-dependent prophylaxis: evidence from Lepidoptera-baculovirus interactions? Ecological Entomology, 23, $100-101$.

Wilson, K., Cotter, S.C., Reeson, A.F. \& Pell, J.K. (2001) Melanism and disease resistance in insects. Ecology Letters, 4, 637-649.

Wilson, K., Thomas, M.B., Blanford, S., Doggett, M., Simspson, S.J. \& Moore, S.L. (2002) Coping with Crowds: density-dependent disease resistance in desert locusts. Proceedings of the National Academy of Sciences USA, 99, 5471-5475.

Wilson, K., Knell, R., Boots, M. \& Koch-Osborne, J. (2003) Group living and investment in immune defence: an interspecific analysis. Journal of Animal Ecology, 72, 133-143.

Received 2 September 2011; accepted 11 September 2011

Handling Editor: Sheena Cotter 